\title{
Slit2 promotes tumor growth and invasion in chemically induced skin carcinogenesis
}

\author{
Cuiling Qi ${ }^{1,3}$, Haimei Lan ${ }^{2,3}$, Jie Ye ${ }^{1,3}$, Weidong $\mathrm{Li}^{1}$, Ping Wei ${ }^{1}$, Yang Yang ${ }^{1}$, Simei Guo ${ }^{1}$, Tian Lan ${ }^{1}$, Jiangchao Li ${ }^{1}$, \\ Qianqian Zhang ${ }^{1}$, Xiaodong $\mathrm{He}^{1}$ and Lijing Wang ${ }^{1}$
}

Slit, a neuronal guidance cue, binds to Roundabout (Robo) receptors to modulate neuronal, leukocytic, and endothelial migration. Slit has been reported to have an important effect on tumor growth and metastasis. In the current study, we evaluated the role of Slit2 in skin tumor growth and invasion in mice using a two-step chemical carcinogenesis protocol. We found that Slit2 expression correlated with the loss of basement membrane in the samples of human skin squamous cell carcinoma at different stages of disease progression. Slit2-Tg mice developed significantly more skin tumors than wild-type mice. Furthermore, the skin tumors that occurred in Slit2-Tg mice were significantly larger than those in the wild-type mice 10 weeks after 7,12-dimethylbenz[a]anthracene initiation until the end of the experiment. We also found that pathological development of the wild-type mice was delayed compared with that of Slit2-Tg mice. To further investigate the mechanism of increasing tumors in Slit2-Tg mice, we analyzed the expression of 5-bromo-2'-deoxyuridine (BrdU) in mouse skin lesions and found that the number of BrdU-positive cells and microvessel density in skin lesions were significantly higher in Slit2-Tg mice than in wild-type mice. Histological staining of PAS and type IV collagen and the colocalization of Slit2 and type IV collagen demonstrated varying degrees of loss of the basement membrane in the skin lesions from Slit2-Tg mice that were at the stage of carcinoma in situ. However, the basement membrane was well defined in the wild-type mice. In addition, MMP2, but not MMP9, was upregulated in the skin tissue of Slit2-Tg mice. Interruption of Slit2-Robo1 signaling by the antibody R5 significantly repressed the invasive capability of the squamous cell carcinoma cell line A431. Taken together, our findings reveal that Slit2 promotes DMBA/TPA-induced skin tumorigenesis by increasing cell proliferation, microvessel density, and invasive behavior of cutaneous squamous cell carcinoma, along with loss of basement membrane, by upregulation of MMP2 expression.

Laboratory Investigation (2014) 94, 766-776; doi:10.1038/labinvest.2014.70; published online 19 May 2014

KEYWORDS: basement membrane; collagen IV; DMBA (7;12-(dimethylbenz[a]anthracene)); skin tumorigenesis; Slit2; TPA (12-Otetradecanoylphorbol-13-acetate)

Skin cancer is one of the most common malignant tumors. Approximately 2 to 3 million cases of nonmelanoma skin cancer occur annually worldwide, and its incidence has been rising rapidly over the past several decades. ${ }^{1}$ Skin cancer develops through a multistage process that includes initiation, promotion, and progression, as shown in experimental animal models. ${ }^{2}$ The two-stage murine skin carcinogenesis model, which comprises two distinctly separate stages (initiation and promotion), is one of the most well-established in vivo models of experimental carcinogenesis. After 7,12-dimethylbenz[a] anthracene (DMBA) initiation, repeated applications of the tumor promoter 12-O-tetradecanoylphorbol-13-acetate (TPA) promote papillomas and eventually carcinomas. ${ }^{3}$ Slit, a member of neuronal guidance cues, has been implicated to play an important role in tumor progression. ${ }^{4}$

The Slit family consists of three members (Slit1, Slit2, and Slit3) that are expressed in the nervous system, whereas Slit-2 and Slit-3 are also found in other tissues, such as skin, lungs, and lymphoid organs. ${ }^{5-8}$ The receptor for Slit is Roundabout (Robo), a transmembrane protein. ${ }^{9-12}$ The interaction of Slits with Robo has a significant effect on axon guidance and neuronal migration. ${ }^{13-15}$

\footnotetext{
'Vascular Biology Research Institute, Guangdong Pharmaceutical University, Guangzhou, China and ²Dermatological Department, NanFang Hospital, Guangzhou, China

Correspondence: Dr L Wang, PhD, Vascular Biology Research Institute, Guangdong Pharmaceutical University, Guangzhou Higher Education Mega Center, Guangzhou, Guangdong 510006, China.

E-mail: wanglijing0123456@163.com

${ }^{3}$ These authors contributed equally to this work.

Received 11 November 2013; revised 9 April 2014; accepted 10 April 2014
} 
Recently, Slit2 has been reported to play a significant role in carcinogenesis. Some studies have indicated that in human cancers, the Slit2 gene is frequently inactivated by hypermethylation in the promoter region or by allele loss in lung, breast, ovarian, ${ }^{16}$ and colorectal cancers as well as malignant gliomas, ${ }^{17-19}$ suggesting a tumor-suppressive role for Slit2. In breast cancer, lung cancer, and medulloblastoma cells, Slit2 inhibited cell migration and invasion in vitro. ${ }^{20-22} \mathrm{Kim}$ et al ${ }^{22}$ showed that transfection with Slit2 suppressed the metastasis of HT1080 tumor cells in lungs after intravenous inoculation. In addition, lower levels of Slit2 expression were associated with overall poor prognosis and disease-free survival of nonsmall-cell lung cancer (NSCLC) patients. ${ }^{23}$ However, some studies have demonstrated that Slit2 expression is increased in prostate cancer, malignant melanoma, rectal mucinous adenocarcinoma, invasive breast carcinoma, gastric cancer, and hepatocellular carcinoma. ${ }^{24,25}$ Furthermore, it has been reported that Slit-Robo signaling plays a significant role in promoting tumor-induced angiogenesis. ${ }^{25}$ Tumor growth is inhibited in vivo by specific neutralization of the Slit2-Robo1 interaction. $^{25,26}$ It has also been found that Slit2 is a novel regulator of adult lymphangiogenesis and functions to promote lymphatic metastasis of $\beta$-cell carcinomas. ${ }^{27}$ These findings suggest that Slit2 may positively or negatively regulate tumorigenesis, invasion, and metastasis.

To verify whether Slit2 plays a crucial role in skin tumor growth and invasion, we used Slit2-Tg mice in a two-stage skin carcinogenesis protocol based on initiation with DMBA, followed by promotion with TPA. The results from this study have established that Slit2-Tg mice are susceptible to skin tumor formation, mainly because the overexpression of Slit2 results in proliferation of tumor cells. Our work also demonstrates that Slit2 promotes invasive behavior in cutaneous squamous cell carcinoma with loss of basement membrane.

\section{MATERIALS AND METHODS \\ Mice}

C57 mice (permit number: SCXK(Yue)2008-0002) were purchased from Guangdong Medical Animal Experiment Center (Guangdong, China). Slit2 transgenic mice (permit number: SYXK(Yue)2012-0125) were obtained from JianGuo Geng's lab and were generated according to previous reports. ${ }^{27}$ Slit2 gene was detected by PCR using the following primers: Slit2 FW, 5'-CCCTCCGGATCCTTTACCTGTCAA GGTCCT-3'; Slit2 RV, 5'-TGGAGAGAGCTCACAGAACAA GC CACTGTA- ${ }^{\prime}$. All animal studies were approved by the Institutional Laboratory Animal Care and Use Committee.

\section{Human Samples}

Patients with skin diseases agreed to provide skin specimens for histological examination. The samples were obtained from patients who underwent a surgical treatment or biopsy, and the samples were embedded in paraffin. The paraffinembedded samples included normal skin $(n=12)$, epithelial hyperplasia $(n=11)$, carcinoma in situ (CIS; $n=15)$, and carcinoma $(n=13)$. Tissues were collected from the Dermatological Department, NanFang Hospital, Guangzhou, China. The specimens were chosen according to the original pathological diagnosis. The hematoxylin and eosin (H\&E)stained sections were then reevaluated by two experienced pathologists who were blinded to the source of the tissues, according to the World Health Organization classification guidelines.

\section{Two-Stage Skin Carcinogenesis Assay}

In this assay, 7- to 10-week-old mice were used. The dorsal skin of the mice was shaved 3 days before DMBA treatment. First, the mice were treated with $100 \mu \mathrm{g}$ DMBA in $200 \mu \mathrm{l}$ acetone under yellow light, and control mice were treated with $200 \mu \mathrm{l}$ acetone. All the mice were kept in the dark for 12 to $24 \mathrm{~h}$ following DMBA or acetone vehicle treatment. At 1 week after DMBA treatment, the mice were treated with either $2.5 \mu \mathrm{g}$ TPA in $100 \mu \mathrm{l}$ acetone or $100 \mu \mathrm{l}$ acetone alone twice a week that was continued for 20 weeks. Furthermore, mice were observed twice a week, after the diameter of exophytic growths of skin was $>1 \mathrm{~mm}$. Four mice were killed by decapitation after treatment for 8,12 , or 16 weeks. All of the mice were killed after 20 weeks of treatment. The skin growths were removed, fixed in $10 \%$ formalin, and stained with H\&E or hematoxylin and periodic acid-Schiff (PAS) for histopathological examination. All the animal experiment procedures were performed according to the regulations of the China National Guide for the Care and Use of Laboratory Animals.

\section{Evaluation of Tumor Growth}

The skin of the mice that were subjected to the classical twostep skin carcinogenesis protocol was examined twice a week after the skin tumors were $>1 \mathrm{~mm}$ in diameter and the size of the tumors had stabilized. Skin growths that were $>1 \mathrm{~mm}$ in diameter and lasted for at least 2 weeks were regarded as tumors and recorded. Tumor diameters were calculated and recorded every 2 weeks.

\section{Histological Analysis and Pathological Evaluation of Skin Tumors}

After treatment with DMBA/TPA for 8, 12, or 16 weeks and completion of the skin tumor protocol, the mice were killed and the skin lesions were collected, fixed in $10 \%$ formalin, and embedded in paraffin using standard procedures. Sections $(3 \mu \mathrm{m})$ were stained with $\mathrm{H} \& \mathrm{E}$ or PAS reagent. The sections that were stained with H\&E were evaluated by three independent observers who were blinded to the source of the tissues. The specimens were classified as hyperplasia, dysplasia, CIS, or carcinoma. Frozen sections $(6 \mu \mathrm{m})$ were cut using a cryostat and were then fixed in acetone for $10 \mathrm{~min}$. The slides were then stored at $-20{ }^{\circ} \mathrm{C}$ for immunofluorescence after being dried for $2 \mathrm{~h}$ at room temperature. 


\section{Measurement of Epidermal Thickness}

The H\&E-stained tissue sections were photographed using a Leica microscope. The thickness of the epidermis was measured in the images using the Image-Pro Plus (IPP) software. A line connecting the intact stratum corneum to the dermalepidermal junction was drawn by hand, and the IPP software recorded the length of each line segment drawn. Twenty line segments were drawn on each of the five sections per slide for a total population of 100 thickness measurements per skin sample.

\section{Immunohistochemical and Immunofluorescence Assay}

For immunohistochemistry, the paraffin sections were retrieved under high pressure in $10 \mathrm{mM}$ citrate buffer ( $\mathrm{pH}$ 6.0). The sections were then blocked with $0.3 \% \mathrm{H}_{2} \mathrm{O}_{2}$ solution for $30 \mathrm{~min}$ at $37^{\circ} \mathrm{C}$, followed by serum for $50 \mathrm{~min}$, and were then incubated with anti-BrdU (ZSGB-BIO), CD31 (Santa Cruz), MMP2 (Santa Cruz), or MMP9 (Santa Cruz) antibody overnight at $4{ }^{\circ} \mathrm{C}$. The next day, the sections were incubated with secondary antibody (ZSGB-BIO) for $50 \mathrm{~min}$. Finally, sections were stained with diaminobenzidine substrate (Pierce) and counterstained with hematoxylin. For immunofluorescence, the frozen sections were boiled for antigen retrieval in $10 \mathrm{mM}$ citrate buffer for $10 \mathrm{~min}$ at $100^{\circ} \mathrm{C}$ and cooled to room temperature for $1.5 \mathrm{~h}$. After nonspecific antibody binding was blocked with serum, the sections were incubated with antibodies for Slit2 (Abcam), Robo1 (Abcam), or collagen type IV (Millipore) overnight at $4{ }^{\circ} \mathrm{C}$. The slides were then incubated for $50 \mathrm{~min}$ at $37^{\circ} \mathrm{C}$ with secondary antibody Alexa Fluor 488-conjugated donkey antimouse IgG (Invitrogen) or Alexa Fluor 555-conjugated goat anti-rabbit IgG (Invitrogen). For nuclear staining, slides were incubated with 4',6-diamidino-2-phenylindole (DAPI; Sigma) for $10 \mathrm{~min}$ at room temperature. The slides were then rinsed and coverslipped with fluorescent mounting medium (ZSGB-BIO). The stained sections were evaluated using a confocal laser scanning microscope.

\section{Migration Assay}

The migration assay was investigated using a 48-well micro chemotaxis chamber (Neuro Probe). The PVP-free polycarbonate membranes ( $8 \mu \mathrm{m}$ pore size) were hydrated with $1 \%$ gelatin for $60 \mathrm{~min}$. Then, $26 \mu \mathrm{l}$ of EMDM medium with $10 \%$ FBS was added to the lower chambers. Furthermore, A431 cells $\left(5 \times 10^{5}\right.$ cells $\left./ \mathrm{ml}\right)$ were cultivated in $50 \mu \mathrm{l}$ serumfree medium (with or without R5) in the upper chambers at $37^{\circ} \mathrm{C}$ for $12 \mathrm{~h}$. The filters were then fixed in $4 \%$ paraformaldehyde and stained with $1 \%$ crystal violet for $3 \mathrm{~h}$. The migrated cells were photographed and counted.

\section{Invasion Assay}

Cell invasion was investigated using a Transwell chamber (Millipore) with Matrigel (BD). The Transwell chamber membranes $(8 \mu \mathrm{m}$ pore) were hydrated with serum-free medium for $2 \mathrm{~h}$. After hydration, the Transwell chambers were coated with $20 \mu \mathrm{l}$ Matrigel and were incubated at $37^{\circ} \mathrm{C}$ for $2 \mathrm{~h}$. The A431 cells $\left(3 \times 10^{5} \mathrm{cells} / \mathrm{ml}\right)$ were added to the upper chambers in $200 \mu \mathrm{l}$ serum-free medium (with or without R5), whereas $600 \mu \mathrm{l}$ of DMEM medium with $10 \%$ FBS was added to the lower chambers of the 24-well plate. The plate was incubated at $37^{\circ} \mathrm{C}$ for $24 \mathrm{~h}$. After $24 \mathrm{~h}$, the invaded cells were fixed in $4 \%$ paraformaldehyde and stained by $1 \%$ crystal violet for $20 \mathrm{~min}$. Noninvasive cells were wiped off by cotton swabs. The invading cells were photographed and counted.

\section{Statistical Analysis}

All data are shown as mean values \pm s.e.m. Statistical significance was determined by Mann-Whitney $U$-test and Wilcoxon $t$-test. For all tests, $P<0.05$ or $<0.01$ was considered statistically significant or very significant.

\section{RESULTS \\ Expression of Slit2 and Type IV Collagen in Human Skin Tissue}

We investigated the correlation of Slit2 expression with the loss of basement membrane in 39 samples of human skin squamous cell carcinoma at different stages of disease progression. The pathological stages of the tissue used were normal, hyperplasia, CIS, and carcinoma. Notably, Slit2 was rarely expressed in the normal skin ( $0 / 12$ cases, $0 \%$ positive) or in hyperplastic tissues ( $1 / 11$ cases, $9 \%$ positive) (Figure 1a). Furthermore, a well-defined basement membrane was observed in the skin lesions from normal skin and hyperplastic tissue by type IV collagen staining (Figure 1b). Expression of Slit2 was displayed with increasing frequency in samples of CIS (10/15 cases, $67 \%$ positive) and carcinoma (10/13 cases, $77 \%$ positive) (Figure 1a). Slit2 was remarkably increased in CIS tissues compared with hyperplastic skin, in which there was almost no expression of Slit2. However, there were varying degrees of loss of basement membrane in the skin lesions from CIS and carcinoma (Figure 1b). These results suggest that Slit2 might be involved in skin tumorigenesis.

\section{Slit2 Promotes Chemically Induced Skin Tumorigenesis}

To evaluate our in vivo findings in humans, Slit2-Tg mice and wild-type mice (wild-type, $n=40$ and Slit2-Tg, $n=34$ ) were used to establish the DMBA/TPA two-stage carcinogenesis model $^{28}$ that induces de novo skin tumors.

As shown in Figure 2a, formation of skin papilloma was induced by DMBA/TPA treatment of the skin in both Slit2$\mathrm{Tg}$ and wild-type mice. Early tumor formation was found on the back of wild-type $(n=28)$ and Slit2-Tg $(n=22)$ mice 7 weeks after DMBA initiation (Figure 2b). Compared with wild-type mice, the number of skin tumors significantly increased in Slit2-Tg mice $(P<0.05)$ between 12 and 16 weeks after DMBA treatment. Furthermore, the tumors that appeared in Slit2-Tg mice between 10 and 16 weeks after DMBA treatment were significantly larger than those in 
a

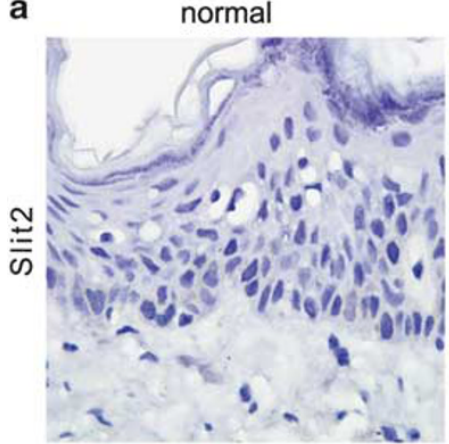

hyperplasia

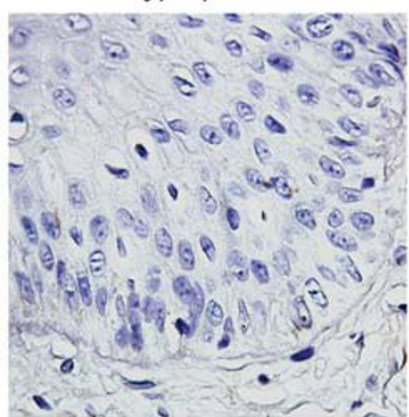

carcinoma in situ

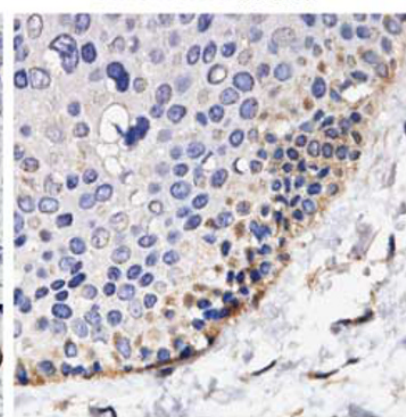

carcinoma

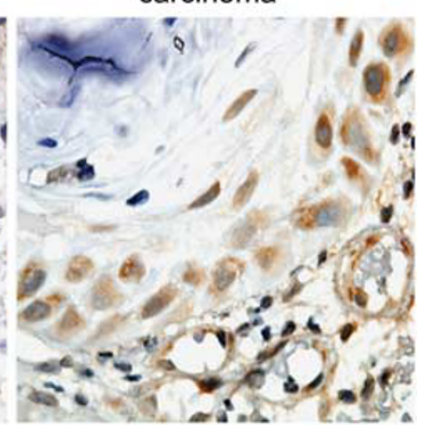

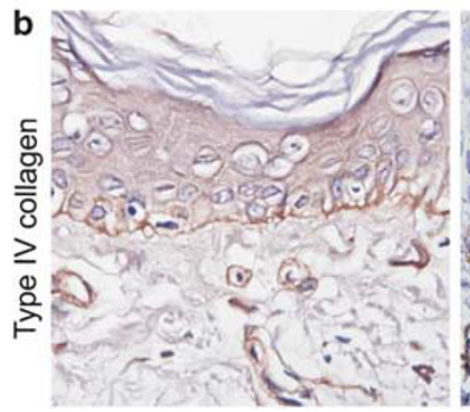
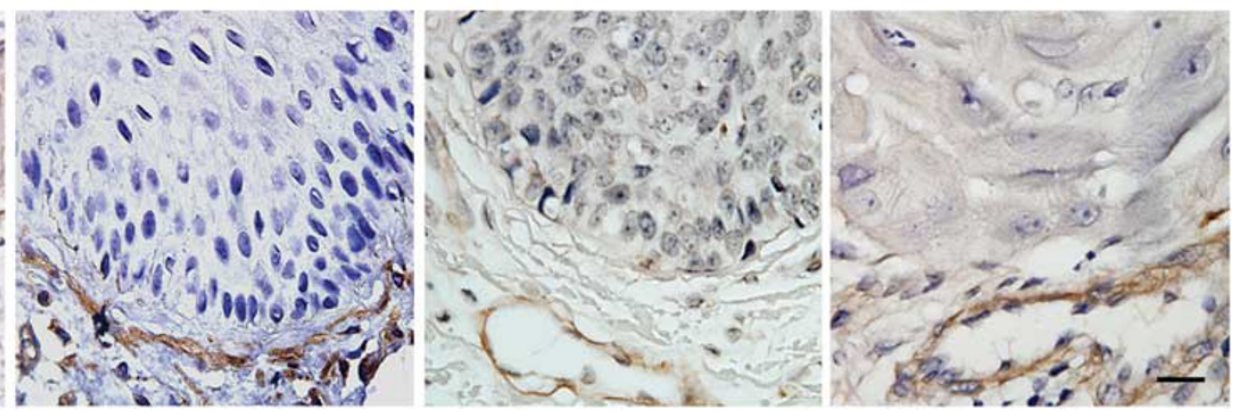

Figure 1 Expression of Slit2 and type IV collagen in human skin tissues. (a) Slit2 was not expressed in human normal and hyperplastic skin tissues. However, expression of Slit2 was remarkably increased in carcinoma in situ (CIS) and carcinoma tissues. (b) There was a well-defined basement membrane in normal and hyperplastic human skin tissues, as observed by type IV collagen staining. The basement membrane showed varying degrees of loss in the skin lesions with CIS and carcinoma. Scale bar: $20 \mu \mathrm{m}$.
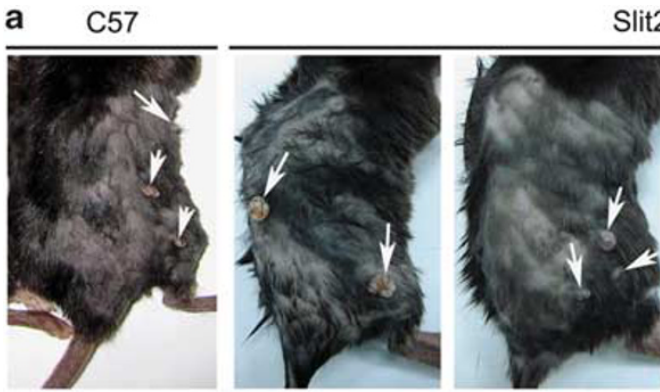

Slit2-Tg
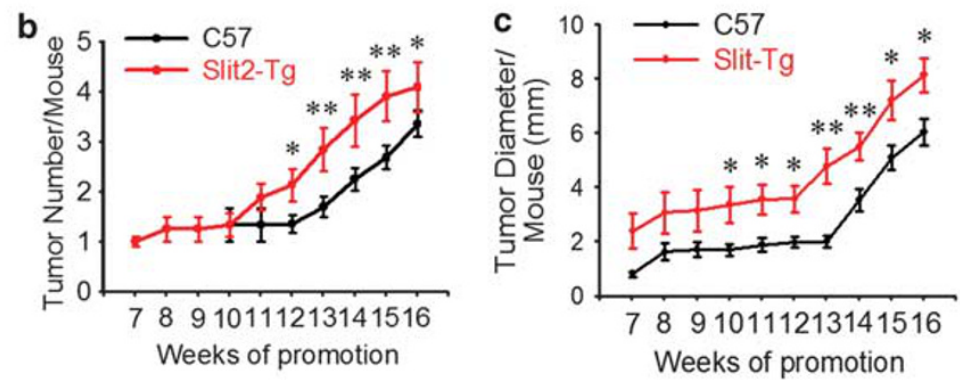

Figure 2 Slit2 promotes chemically induced skin tumorigenesis. Two-stage chemical carcinogen testing was performed in wild-type or Slit2-Tg mice as described in the Materials and Methods. (a) Representative photographs of the back of mice in different populations 16 weeks after DMBA initiation. (b) The mean average number of tumors per mouse over time. (c) Average skin lesion diameters in wild-type and Slit2-Tg mice. Student's $t$-test was used for statistical analysis. ${ }^{*} P<0.05$ and ${ }^{* *} P<0.01$. 
a
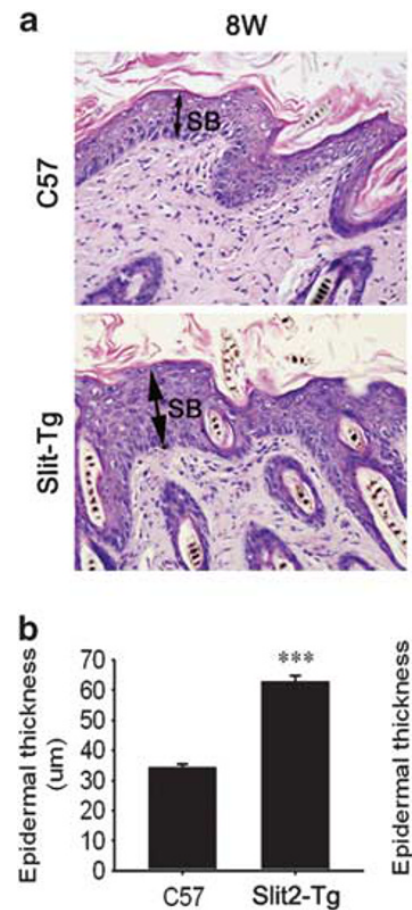

$12 \mathrm{~W}$
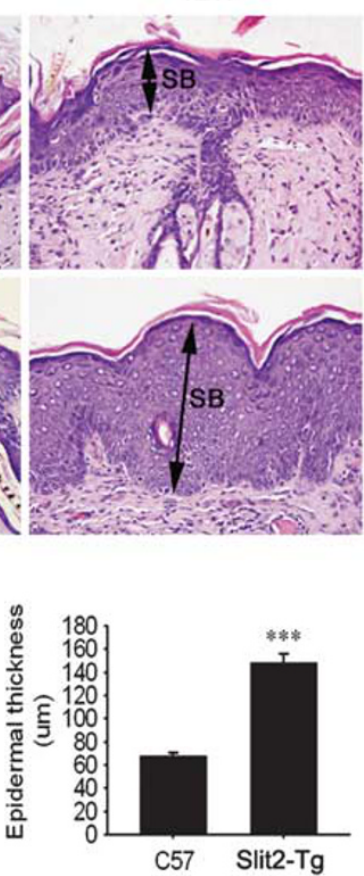

16W
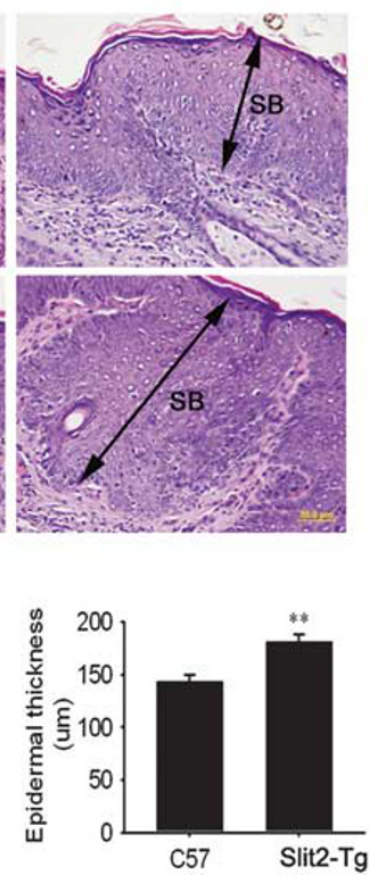

Figure 3 Histological characteristics of formation of skin tumors and epidermal thickness. (a) The epidermis of wild-type mice and Slit2-Tg mice after 8 , 12 , and 16 weeks of the classical two-stage chemical carcinogenesis protocol revealed striking abnormalities in epidermal architecture consistent with tumor formation, including the appearance of pseudohorn cysts. (b) Epidermal thickness in wild-type and Slit2-Tg mice. SB, suprabasal compartment.

wild-type mice $(P<0.05$ and $P<0.01$; Figure $2 \mathrm{c})$. These data suggest that Slit2 promotes the initiation and development of mouse skin tumors when induced by DMBA/TPA treatment.

\section{Effect of Slit2 on Characteristics of Skin Tumor Progression and Epidermal Hyperplasia}

DMBA/TPA treatment caused the epidermis to gradually demonstrate abnormalities in morphological architecture consistent with tumor formation, including a much thicker suprabasal compartment, an expanded stratum corneum, and a more dispersed granular layer (Figure 3a). In addition, it is very evident that epidermal structures invaginate into the dermis (Figure 3a). Furthermore, pathological development in wild-type mice was delayed compared with that of Slit2-Tg mice (Figure 3a). Figure 3b summarizes the epidermal thickness that was determined from H\&E-stained sections in wild-type and Slit2-Tg mice after 8, 12, and 16 weeks of the classical two-stage chemical carcinogenesis protocol. As expected, epidermal thickness in Slit2-Tg mice was increased compared with that of the corresponding aged wild-type mice.

\section{Slit2 Promotes DMBA/TPA-Induced Cell Proliferation and Angiogenesis}

To understand whether increased tumor volume in Slit2-Tg mice was due to the promotion of cell proliferation and angiogenesis, expression of 5-bromo- $2^{\prime}$-deoxyuridine (BrdU) and CD31 in mouse skin lesions was analyzed. As we predicted, the number of BrdU-positive cells in skin lesions was significantly higher in Slit2-Tg mice than in wild-type mice that were treated with DMBA/TPA between 8 and 16 weeks (Figure 4a). Immunohistochemical staining with anti-CD31 antibody revealed less neovasculature in the tissues from wild-type mice compared with Slit2-Tg mice (Figure 4b). Statistical analysis further indicated a reduction of MVD in the tissues of wild-type mice when compared with the MVD in the tissues of Slit2-Tg mice (Figure $4 \mathrm{~b}$ ).

\section{Regional Losses of Basement Membrane in Skin Lesions in CIS}

Because Slit2 could promote DMBA/TPA-induced tumor growth, we then examined the effect of Slit2 on tumor invasion. All sections containing epithelial components were analyzed for an intact basement membrane by histological staining of PAS and type IV collagen. A well-defined basement membrane (dashed line) was identified in skin lesions from Slit2-Tg mice at the stage of hyperplasia and in skin lesions from wild-type mice in the stages of hyperplasia and CIS, as shown by PAS or collagen IV staining (Figures $5 \mathrm{a}$ and b). There were varying degrees of loss of the basement membrane (arrowhead) in the skin lesions of Slit2-Tg mice that were at the stages of CIS and carcinoma, and similarly in skin lesions of wild-type mice that were in the stage of carcinoma (Figures 5a and b). 
a
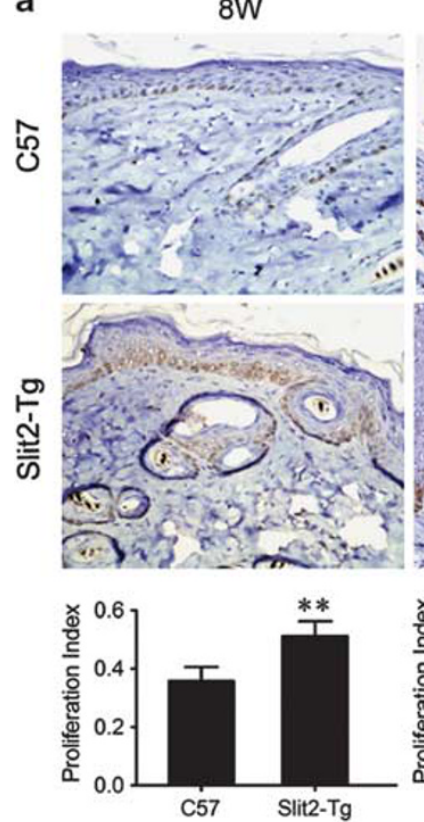

$8 \mathrm{~W}$
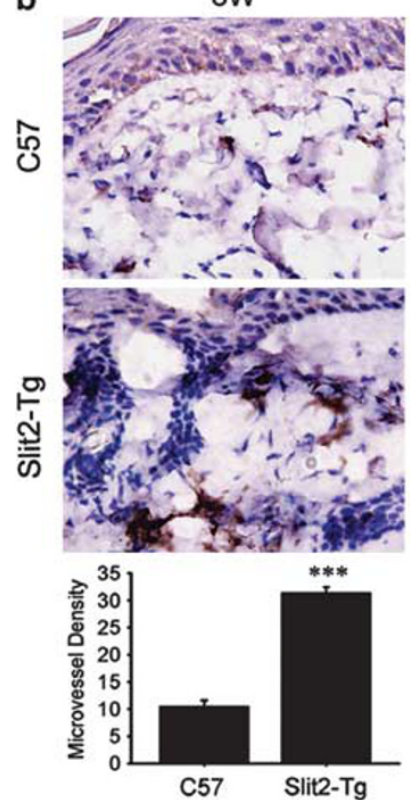

$12 \mathrm{~W}$
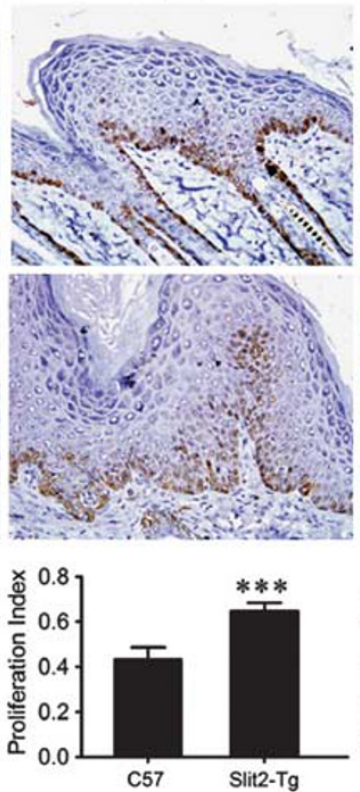

$12 \mathrm{~W}$
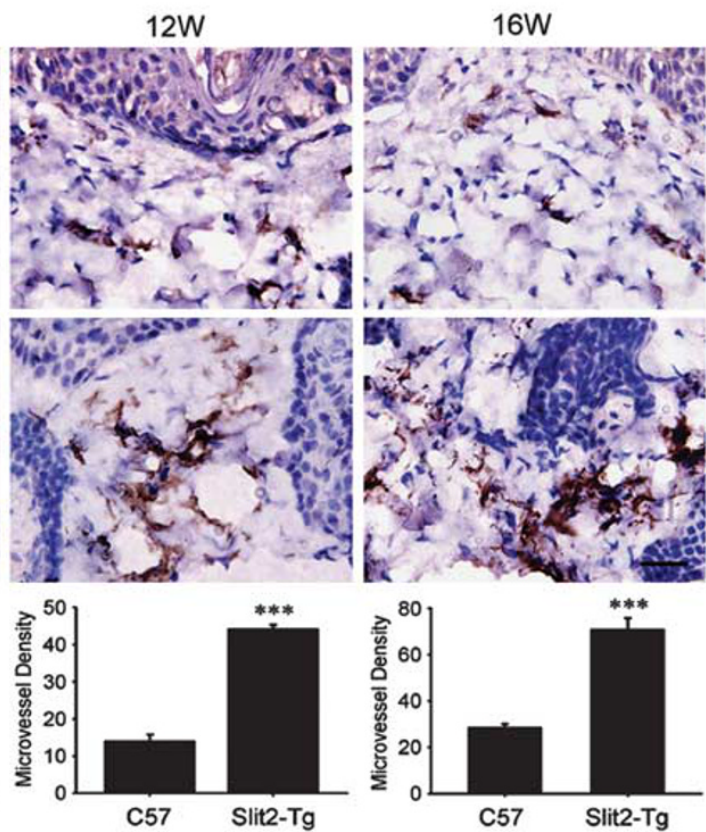

$16 \mathrm{~W}$
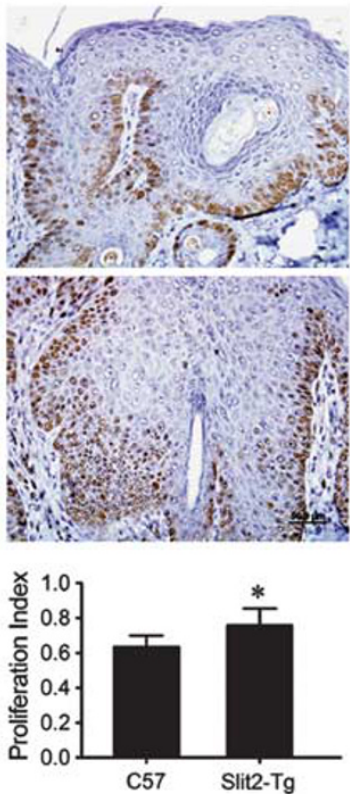

$16 \mathrm{~W}$

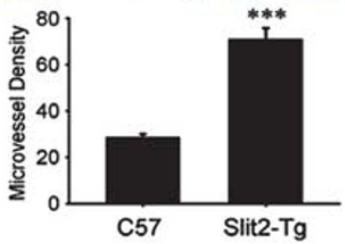

Figure 4 Immunohistochemical staining for BrdU in the skin lesions from Slit2-Tg mice and wild-type mice treated with DMBA/TPA. (a) The number of BrdU-positive epidermal cells was counted from at least 100 cells in five separate fields for each section at every period $(n=4)$. (b) The staining of CD31 for neovasculatures in TPA/DMBA-induced carcinogenesis. ${ }^{*} P<0.05,{ }^{*} P<0.01$ and ${ }^{* * *} P<0.001$.

Figure 5 Periodic acid-Schiff (PAS) staining and IF staining for type IV collagen in the skin lesions of Slit2-Tg mice and wild-type mice. (a) PAS staining demonstrates partial loss of PAS-positive basement membrane in skin lesions of Slit2-Tg mice in the stage of CIS and carcinoma and in skin lesions of wild-type mice in the stage of CIS. Note a continuous linear pattern in the basement membrane (BM) of skin lesions from Slit2-Tg mice in the stage of hyperplasia and that of wild-type mice in the stage of hyperplasia and CIS. (b) BM was revealed by type IV collagen staining (red). DAPI (blue) was used as a nuclear stain. Arrowheads indicate basement membrane-positive location and arrows indicate basement membrane-negative location. Scale bar: $20 \mu \mathrm{m}$. 

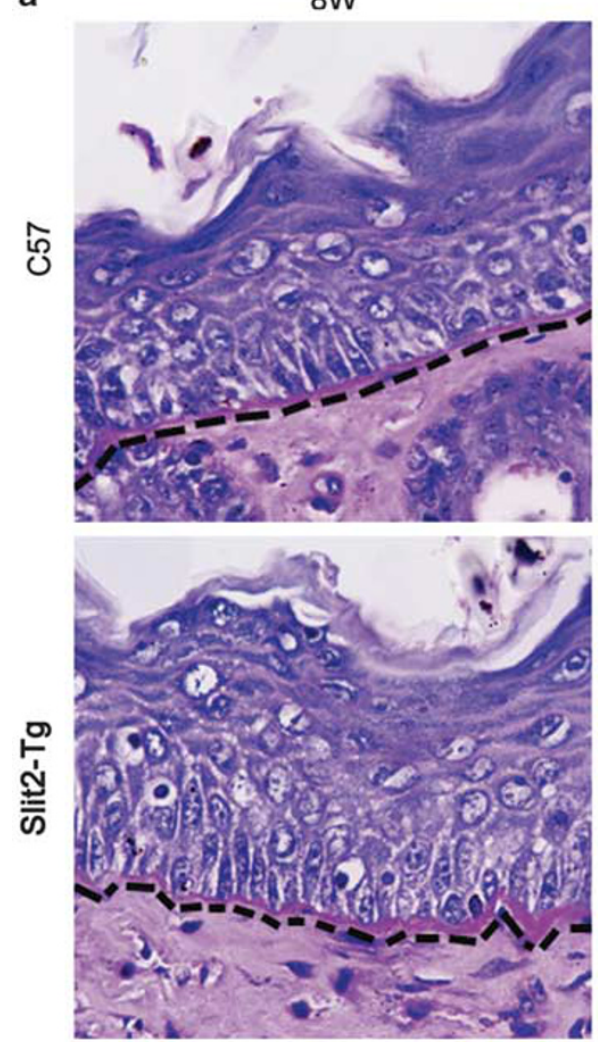

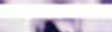
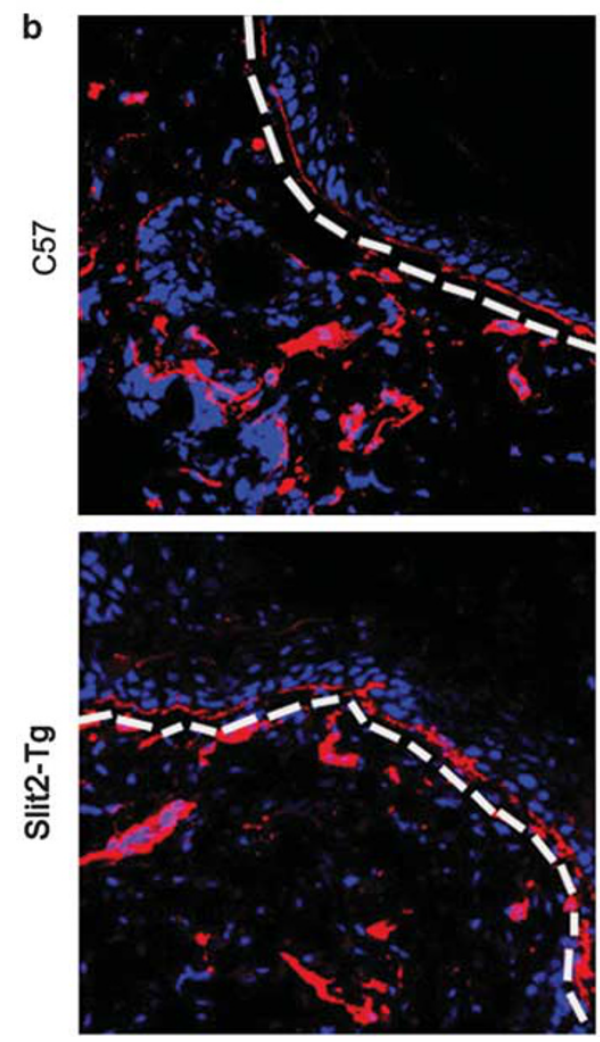

$12 \mathrm{~W}$
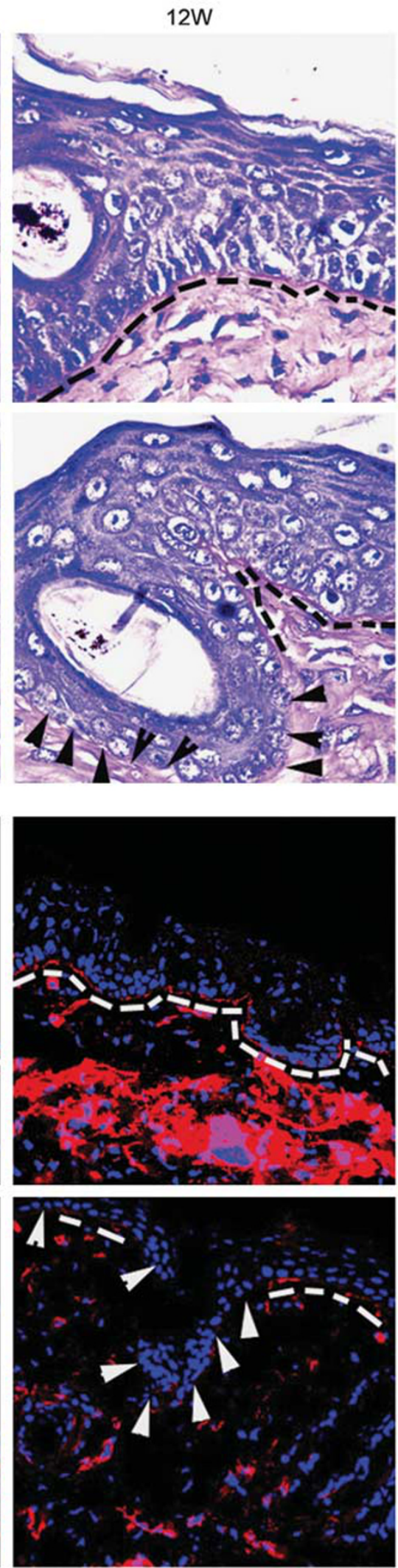
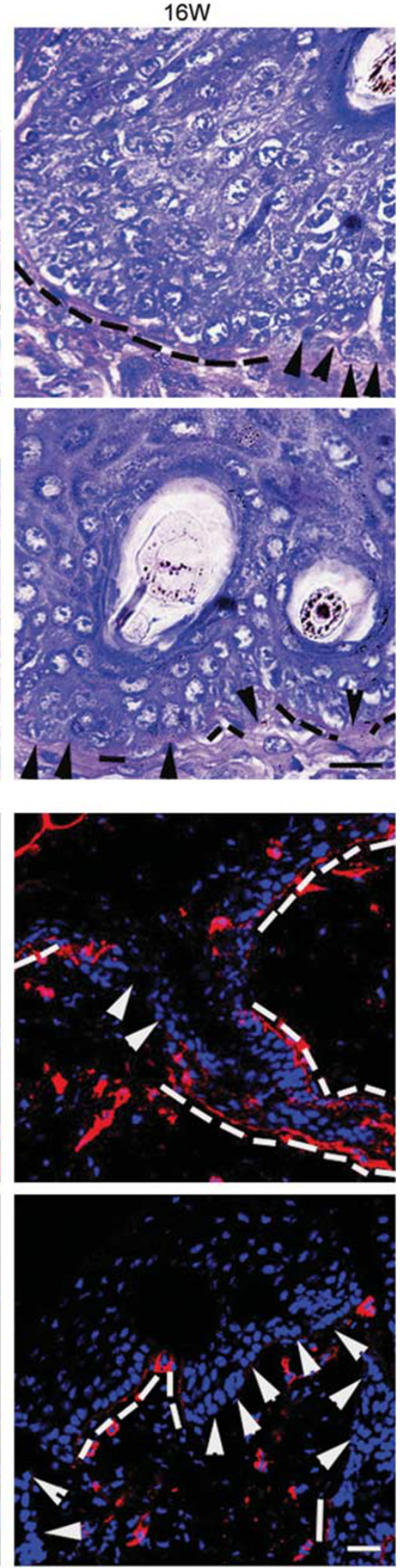

Figure 5 For caption see page 771. 
a
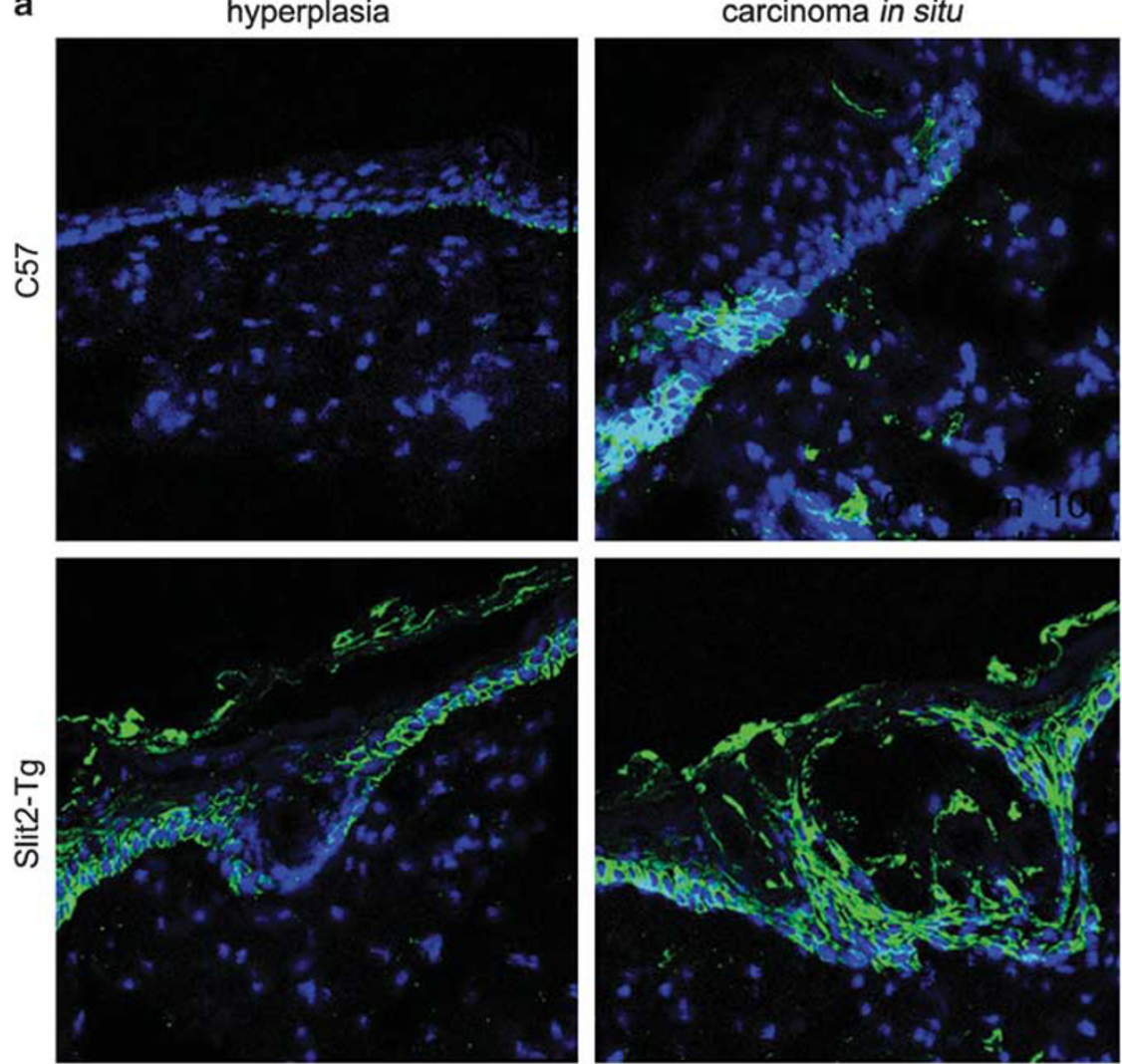

carcinoma
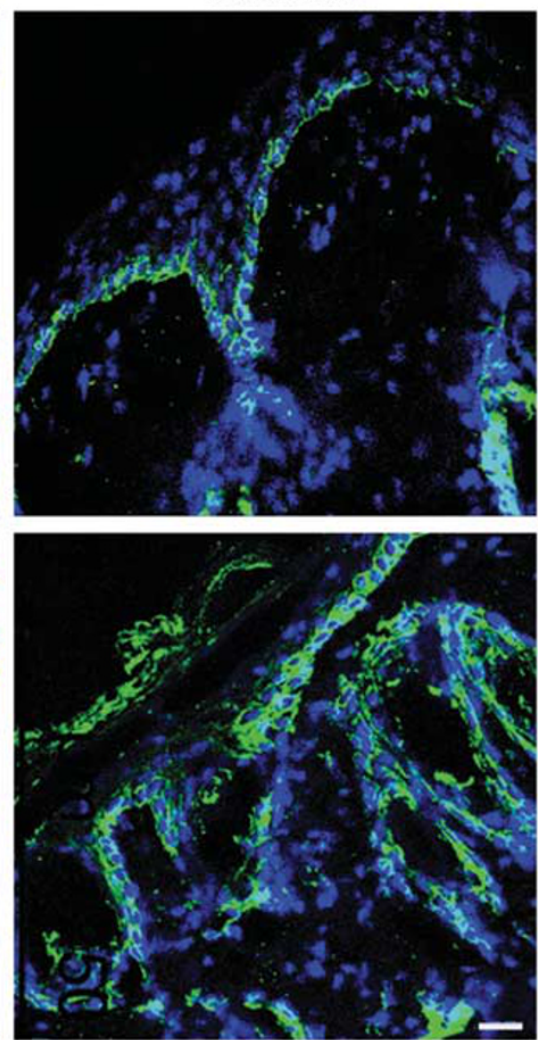

b Ttype IV collagen/Slit2/DAPI

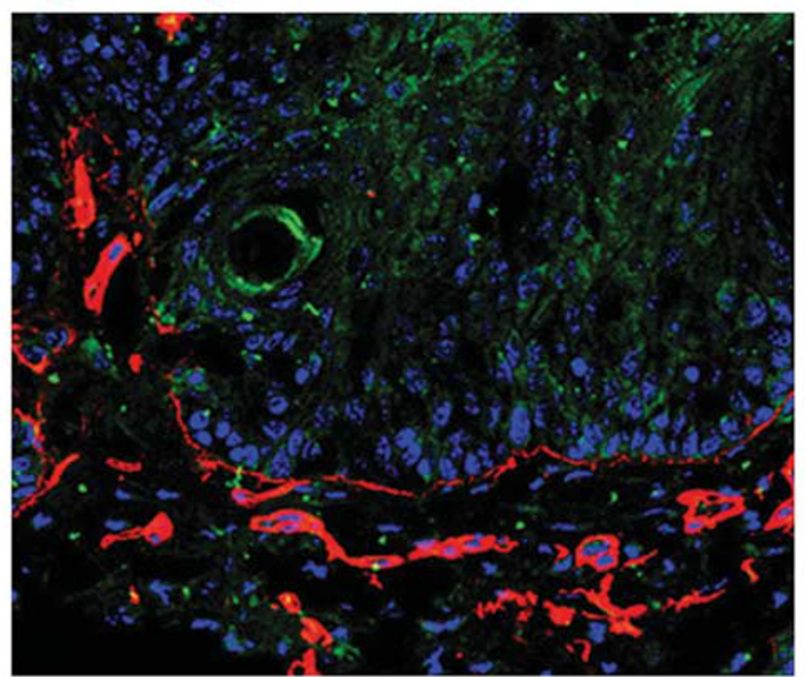

C57

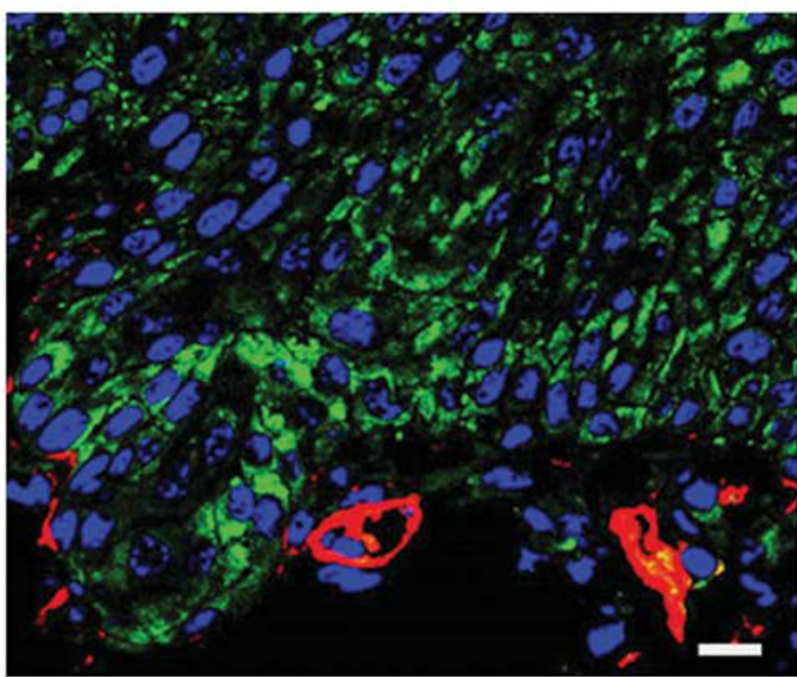

Slit2-Tg

Figure 6 Loss of basement membrane is correlated with Slit2 overexpression. (a) Expression of Slit2 in the skin lesions from Slit2-Tg and C57 mice. (b) Immunofluorescent staining for type IV collagen (red) and Slit2 (green) in the skin lesions from Slit2-Tg mice and wild-type mice in the stage of CIS. Type IV collagen expression in the skin lesions from Slit2-Tg mice is partly lost in the BM in Slit2-positive lesions, whereas type IV collagen expression is maintained in the skin lesions from wild-type mice. DAPI (blue) was used as a nuclear stain. Scale bar: $20 \mu \mathrm{m}$.

\section{Loss of Basement Membrane Is Correlated with Slit2 Overexpression}

To further investigate whether Slit2 promotes the loss of the basement membrane, we first studied the expression of Slit2 in the skin lesions of C57 and Slit2-Tg mice. We observed that expression of Slit2 and Robo1 was high in skin lesions from Slit2-Tg mice but was low in skin lesions of wild-type C57 mice (Figure 6a and Supplementary Figure 1). Because of the increased expression of Slit2 in skin lesions from Slit2$\mathrm{Tg}$ mice, coexpression of type IV collagen and Slit2 in mouse 


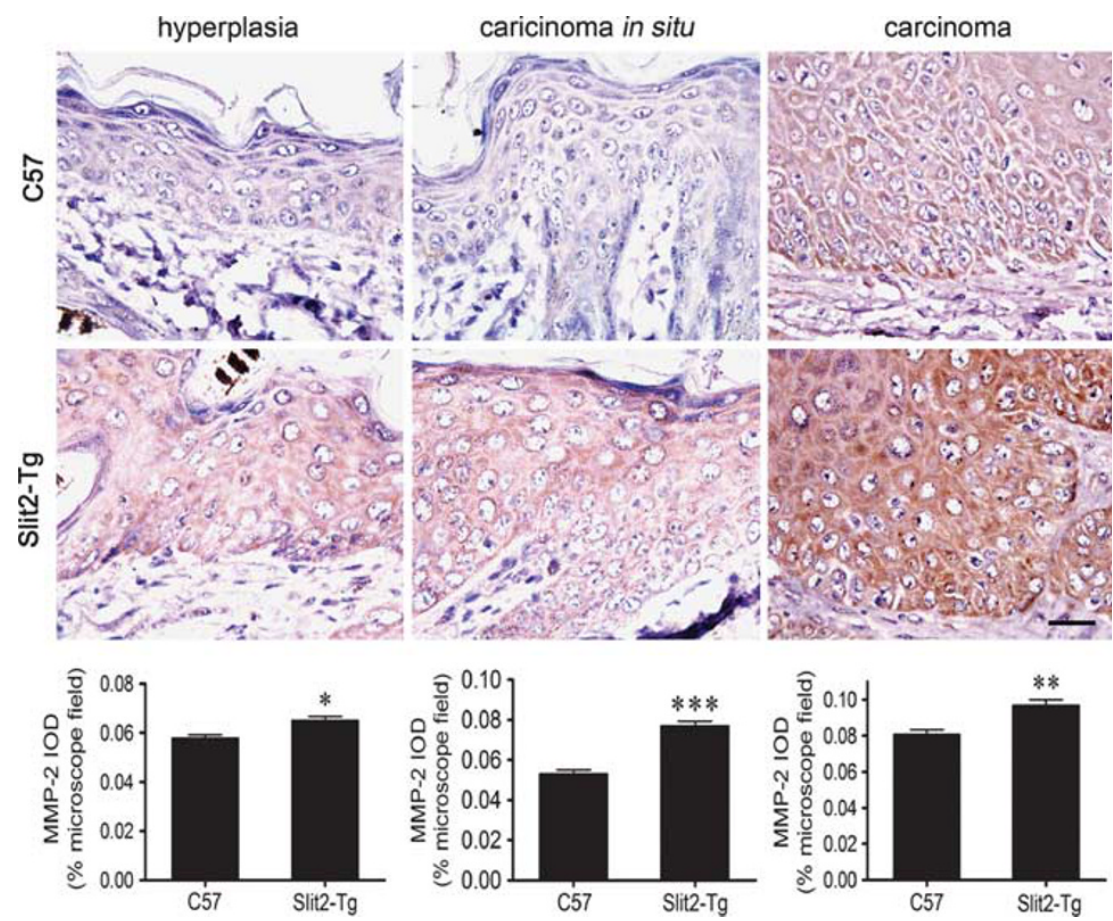

Figure 7 MMP2 expression in the skin lesions from Slit2-Tg and C57 mice. Wild-type and Slit2-Tg mice were killed after treatment with TPA/DMBA for 8,12 , or 16 weeks ( 7 animals at each time point). The skin slides were stained with preimmune $\lg$ or anti-MMP2 antibodies. The statistical analysis demonstrated that MMP2 expression was higher in the tissues from Slit2-Tg mice than that in the tissues of C57 mice. Scale bar: $20 \mu$ m. ${ }^{*} P<0.05$, ${ }^{*} P<0.01$ and ${ }^{* *} P<0.001$.

skin lesions in the CIS stage was analyzed. We observed that there were varying degrees of loss of the basement membrane in Slit2-positive skin lesions from Slit2-Tg mice in the CIS stage (Figure 6b). However, expression of Slit2 was poor in skin lesions from wild-type mice and the basement membrane was essentially intact (Figure 6b).

\section{Slit2 Promoted the Expression of MMP2}

To explore the mechanism of the loss of the basement membrane in the Slit2-Tg mice, we examined the invasionrelated protein using immunohistochemical staining. Immunohistochemical staining analysis revealed that MMP2 expression was high in the tissues from Slit2-Tg mice compared with wild-type mice (Figure 7), whereas MMP9 expression did not change between wild-type mice and Slit2-Tg mice (Supplementary Figure 2).

\section{R5 Inhibited A431 Cell Migration and Invasion}

We further examined whether R5, a mouse monoclonal IgG2b antibody to the first immunoglobulin domain of Robol that blocks the interaction of Robol with Slit2,26 could inhibit A431 cell (human epidermal squamous cell carcinoma cell) migration and invasion compared with the isotype-matched control mouse IgG2b and the blank control. We first found that Slit2 and Robo1 expression was high in A431 cells (Supplementary Figure 3). As the representative micrographs clearly demonstrate, R5 inhibited the A431cells migration in a dose-dependent manner (Figure 8a). Similarly, the invasion capability of A431 cells treated with R5 or IgG was estimated by Matrigel invasion chamber assay. As expected, R5 could significantly repress A431 cell invasion ability compared with the IgG groups (Figure $8 b$ ).

\section{DISCUSSION}

Our previous results have shown that in addition to wellcharacterized functions in axon guidance and neuronal migration, ${ }^{15,29,30}$ Slit2 promotes DMBA/TPA-induced skin tumorigenesis by promoting cell proliferation. Our current results also indicate that Slit2 augments invasive behavior in cutaneous squamous cell carcinoma with loss of basement membrane.

Previously, Slit was known to be a chemorepellent in axon guidance and neuronal migration and an inhibitor in leukocyte chemotaxis. ${ }^{12,15,29-33}$ In addition, studies have indicated that Slit2 may promote tumor growth and metastasis, but the tumor-promoting property of Slit2 has not yet been reported in skin cancers. Our data show that Slit2 promotes chemically induced skin tumorigenesis (Figures 1-3). We also evaluated the effect of Slit2 on the levels of BrdU, a cell proliferation marker. ${ }^{34}$ Immunohistochemical analysis showed that number of BrdU-positive cells and MVD in skin lesions was significantly higher in Slit2-Tg mice than in wild-type mice (Figure 4). Consistent with our data, Slit2 can attract vascular endothelial cells and promote tumor-induced angiogenesis in a Robo1- and phosphatidylinositol kinase-dependent manner. $^{25,26}$ Therefore, it has been suggested that the expression 

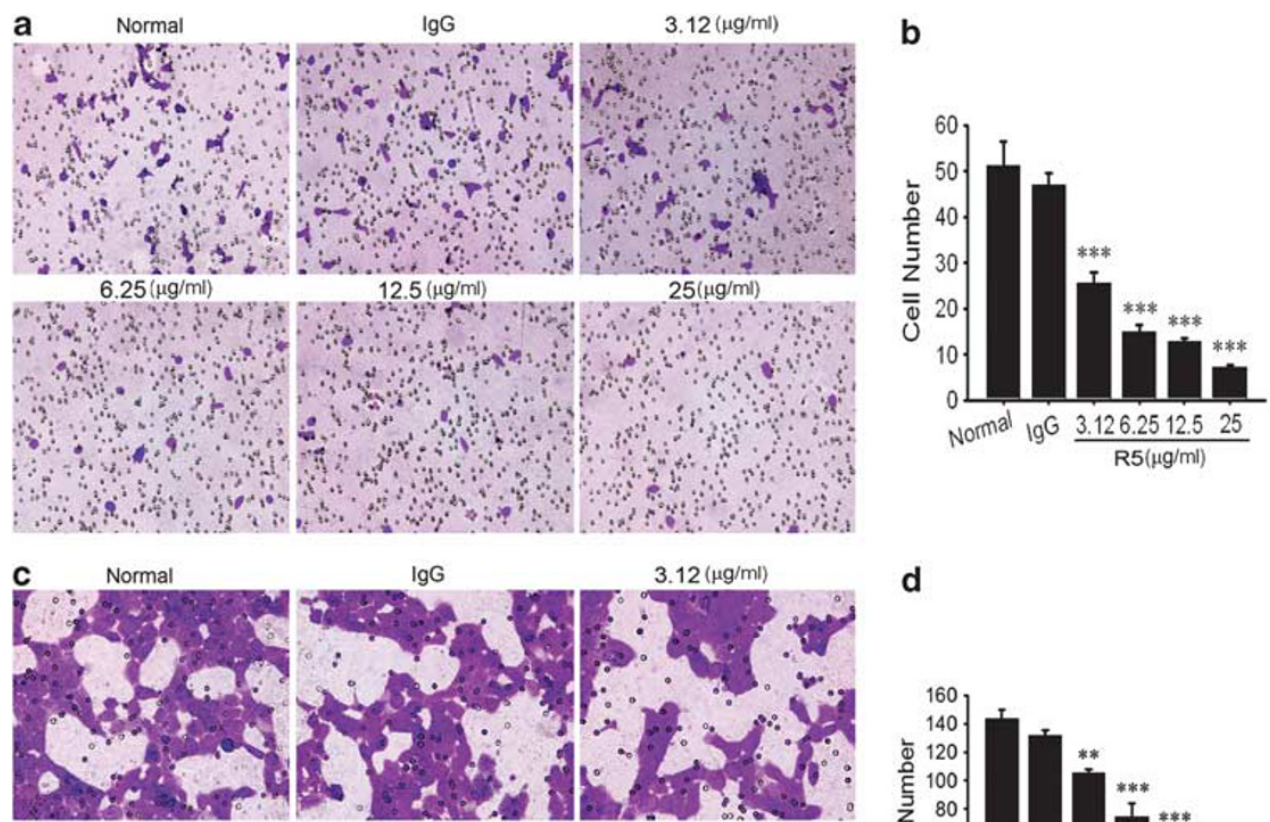

$6.25(\mu \mathrm{g} / \mathrm{m})$
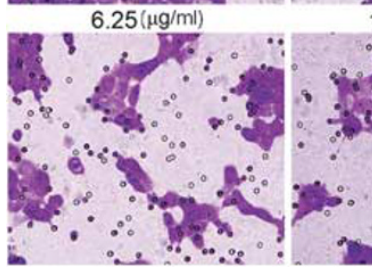

Ig

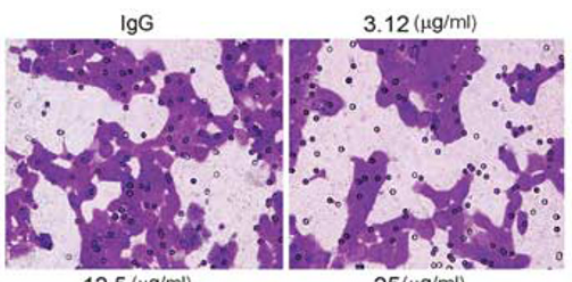

$3.12(\mu \mathrm{g} / \mathrm{ml})$

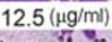

$25(\mu \mathrm{g} / \mathrm{ml}$

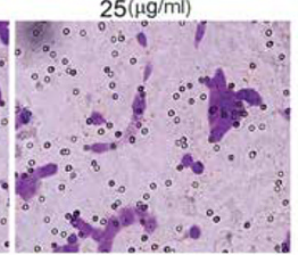

Figure 8 R5 suppresses A431 cell migration and invasion in Transwell assay. (a and b) A431 cells were treated with various concentrations of R5 or IgG. The number of cells passing through the filter was counted after staining with $1 \%$ crystal violet (magnification, $\times 200$ ). (c and d) A431 cells treated with various concentrations of R5 or IgG were added to Matrigel-coated filters and were incubated for $24 \mathrm{~h}$. The number of cells passing through the filter was counted after staining with $1 \%$ crystal violet (magnification, $\times 400$ ). ${ }^{* *} P<0.01$ and ${ }^{* * *} P<0.001$.

of Slit2 can be a useful marker for evaluating tumor malignancy in humans. ${ }^{25}$ Previous studies by Wang et al ${ }^{25}$ have shown that Slit2 protein is expressed in a number of tumor cell lines and solid tumors in a center to periphery gradient. Recently, Wang et $a l^{26}$ showed that in DMBA-induced hamster buccal pouch squamous carcinogenesis, neutralization of Slit2-Robol interaction suppresses tumor angiogenesis and growth. These data are consistent with our mouse model data, indicating that Slit2 has an effect on skin tumor growth through regulating proliferation of tumor cells.

Metastatic spread is a complex process involving a series of sequential events, including detachment of tumor cells from the primary site, invasion through the basement membrane and the underlying extracellular matrix (ECM), and finally, intravasation. Basement membrane (BM) is a specialized region of extracellular matrix that consists of different components such as proteins and carbohydrates. This substance usually comprises collagen types IV and V, laminin, fibronectin, and sulfated and nonsulfated glycosaminoglycans. ${ }^{35-37}$ Collagen is the most abundant composition of the BM, and among its different types, type IV is the main structural component of the BM. Our results indicate that staining of type IV collagen and PAS demonstrate partial loss of PASpositive basement membrane in the skin lesions of Slit2-Tg mice that are at the stages of CIS and carcinoma and, similarly in wild-type mice that are at the stage of CIS (Figure 5). We also found that overexpression of Slit2 promoted the loss of basement membrane. In line with our data, other literature has verified that the repulsive axon guidance molecule, Slit2, was a novel regulator of adult lymphangiogenesis and functioned to promote lymphatic metastasis of $\beta$-cell carcinomas. ${ }^{27}$

Next, we investigated whether the expression of MMP2 was higher in skin lesions from Slit2-Tg mice compared with those from C57 mice (Figure 7). MMP2 is an extracellular matrix-degrading enzyme ${ }^{38,39}$ and can enable cancer cells to exhibit high invasive and metastatic ability. ${ }^{40}$ Furthermore, our data show that R5 inhibited A431 cell migration and invasion (Figure 8). Therefore, Slit2 may promote invasion of squamous cell carcinoma through regulation of the expression of MMP2.

In summary, we found that Slit 2 increases invasive behavior in cutaneous squamous cell carcinoma with loss of the basement membrane. We also show that Slit2 promotes chemically induced skin tumorigenesis by promoting 
DMBA/TPA-induced cell proliferation and angiogenesis. Our data provide evidence that Slit2 overexpression leads to tumorigenesis through promoting MMP2 expression. Further work investigating the potential role of Slit2 in cancer susceptibility screening and cancer gene therapy is needed.

Supplementary Information accompanies the paper on the Laboratory Investigation website (http://www.laboratoryinvestigation.org)

\section{ACKNOWLEDGMENTS}

We thank our lab members for their discussion and Xiao-Ming Zhou for technical assistance. This work was supported by grants from the Ministry of Science and Technology of China (National Basic Research Program of China 2010 CB529702 to Lijing Wang), National Science Foundation of China (31271455 to Lijing Wang), and the Medical Science Research Foundation of Guangdong Province of China (no. B2012181 to Qianqian Zhang).

\section{DISCLOSURE/CONFLICT OF INTEREST}

The authors declare no conflict of interest.

1. Yeong LT, Hamid RA, Yazan LS, et al. Isolation of a quinonerich fraction from Ardisia crispa roots and its attenuating effects on murine skin tumorigenesis. Asian Pac J Cancer Prev 2013;14: 2301-2305.

2. Meeran SM, Vaid M, Punathil T, et al. Dietary grape seed proanthocyanidins inhibit 12-O-tetradecanoyl phorbol-13-acetate-caused skin tumor promotion in 7,12-dimethylbenz[a]anthracene-initiated mouse skin, which is associated with the inhibition of inflammatory responses. Carcinogenesis 2009;30:520-528.

3. Rothberg JM, Jacobs JR, Goodman CS, et al. slit: an extracellular protein necessary for development of midline glia and commissural axon pathways contains both EGF and LRR domains. Genes Dev 1990;4:2169-2187.

4. Yuan W, Zhou L, Chen JH, et al. The mouse SLIT family: secreted ligands for $\mathrm{ROBO}$ expressed in patterns that suggest a role in morphogenesis and axon guidance. Dev Biol 1999;212:290-306.

5. Holmes GP, Negus K, Burridge L, et al. Distinct but overlapping expression patterns of two vertebrate slit homologs implies functional roles in CNS development and organogenesis. Mech Dev 1998;79: 57-72.

6. Itoh A, Miyabayashi T, Ohno M, et al. Cloning and expressions of three mammalian homologues of Drosophila slit suggest possible roles for Slit in the formation and maintenance of the nervous system. Brain Res Mol Brain Res 1998;62:175-186.

7. Marillat V, Cases O, Nguyen-Ba-Charvet KT, et al. Spatiotemporal expression patterns of slit and robo genes in the rat brain. J Comp Neurol 2002;442:130-155.

8. Piper M, Georgas K, Yamada T, et al. Expression of the vertebrate Slit gene family and their putative receptors, the Robo genes, in the developing murine kidney. Mech Dev 2000;94:213-217.

9. Kidd $\mathrm{T}$, Brose $\mathrm{K}$, Mitchell KJ, et al. Roundabout controls axon crossing of the CNS midline and defines a novel subfamily of evolutionarily conserved guidance receptors. Cell 1998;92:205-215.

10. Kidd T, Bland KS, Goodman CS. Slit is the midline repellent for the robo receptor in Drosophila. Cell 1999;96:785-794.

11. Brose K, Bland KS, Wang KH, et al. Slit proteins bind Robo receptors and have an evolutionarily conserved role in repulsive axon guidance. Cell 1999;96:795-806.

12. Li HS, Chen JH, Wu W, et al. Vertebrate slit, a secreted ligand for the transmembrane protein roundabout, is a repellent for olfactory bulb axons. Cell 1999;96:807-818.

13. Guan H, Zu G, Xie Y, et al. Neuronal repellent Slit2 inhibits dendritic cell migration and the development of immune responses. J Immunol 2003;171:6519-6526.

14. Wu JY, Feng L, Park HT, et al. The neuronal repellent Slit inhibits leukocyte chemotaxis induced by chemotactic factors. Nature 2001;410:948-952.
15. Wong K, Park HT, Wu JY, et al. Slit proteins: molecular guidance cues for cells ranging from neurons to leukocytes. Curr Opin Genet Dev 2002:12:583-591.

16. Yiin JJ, Hu B, Jarzynka MJ, et al. Slit2 inhibits glioma cell invasion in the brain by suppression of Cdc42 activity. Neuro Oncol 2009;11:779-789.

17. Dallol A, Da Silva NF, Viacava P, et al. SLIT2, a human homologue of the Drosophila Slit2 gene, has tumor suppressor activity and is frequently inactivated in lung and breast cancers. Cancer Res 2002;62:5874-5880.

18. Dallol $A$, Krex $D$, Hesson $L$, et al. Frequent epigenetic inactivation of the SLIT2 gene in gliomas. Oncogene 2003;22:4611-4616.

19. Mertsch S, Schmitz N, Jeibmann A, et al. Slit2 involvement in glioma cell migration is mediated by Robo1 receptor. J Neurooncol 2008;87:1-7.

20. Prasad A, Fernandis AZ, Rao Y, et al. Slit protein-mediated inhibition of CXCR4-induced chemotactic and chemoinvasive signaling pathways in breast cancer cells. J Biol Chem 2004;279:9115-9124.

21. Werbowetski-Ogilvie TE, Seyed Sadr M, Jabado N, et al. Inhibition of medulloblastoma cell invasion by Slit. Oncogene 2006;25:5103-5112.

22. Kim HK, Zhang $\mathrm{H}$, Li H, et al. Slit2 inhibits growth and metastasis of fibrosarcoma and squamous cell carcinoma. Neoplasia 2008;10: $1411-1420$.

23. Tseng RC, Lee SH, Hsu HS, et al. SLIT2 attenuation during lung cancer progression deregulates beta-catenin and E-cadherin and associates with poor prognosis. Cancer Res 2010;70:543-551.

24. Latil A, Chene L, Cochant-Priollet B, et al. Quantification of expression of netrins, slits and their receptors in human prostate tumors. Int J Cancer 2003;103:306-315.

25. Wang $B$, Xiao Y, Ding BB, et al. Induction of tumor angiogenesis by SlitRobo signaling and inhibition of cancer growth by blocking Robo activity. Cancer Cell 2003;4:19-29.

26. Wang LJ, Zhao Y, Han B, et al. Targeting Slit-Roundabout signaling inhibits tumor angiogenesis in chemical-induced squamous cell carcinogenesis. Cancer Sci 2008;99:510-517.

27. Yang XM, Han $H X$, Sui $F$, et al. Slit-Robo signaling mediates lymphangiogenesis and promotes tumor lymphatic metastasis. Biochem Biophys Res Commun 2010;396:571-577.

28. Owens DM, Wei S, Smart RC. A multihit, multistage model of chemical carcinogenesis. Carcinogenesis 1999;20:1837-1844.

29. Bashaw GJ, Goodman CS. Chimeric axon guidance receptors: the cytoplasmic domains of slit and netrin receptors specify attraction versus repulsion. Cell 1999;97:917-926.

30. Wu W, Wong $\mathrm{K}$, Chen J, et al. Directional guidance of neuronal migration in the olfactory system by the protein Slit. Nature 1999;400:331-336.

31. Chen JH, Wen L, Dupuis $\mathrm{S}$, et al. The $\mathrm{N}$-terminal leucine-rich regions in Slit are sufficient to repel olfactory bulb axons and subventricular zone neurons. J Neurosci 2001;21:1548-1556.

32. Fernandis AZ, Ganju RK. Slit: a roadblock for chemotaxis. Sci STKE 2001;2001:pe1.

33. Ghose A, Van Vactor D. GAPs in Slit-Robo signaling. Bioessays 2002; 24:401-404.

34. Khan N, Hadi N, Afaq F, et al. Pomegranate fruit extract inhibits prosurvival pathways in human A549 lung carcinoma cells and tumor growth in athymic nude mice. Carcinogenesis 2007;28:163-173.

35. David L, Nesland JM, Holm R, et al. Expression of laminin, collagen IV, fibronectin, and type IV collagenase in gastric carcinoma. An immunohistochemical study of 87 patients. Cancer 1994;73:518-527.

36. De Rosa G, Barra E, Guarino M, et al. Fibronectin, laminin, type IV collagen distribution, and myofibroblastic stromal reaction in aggressive and nonaggressive basal cell carcinoma. Am J Dermatopathol 1994;16:258-267.

37. Nakano K, Naito I, Momota R, et al. The distribution of type IV collagen alpha chains in the mouse ovary and its correlation with follicular development. Arch Histol Cytol 2007;70:243-253.

38. Birchmeier C, Birchmeier W, Gherardi E, et al. Met, metastasis, motility and more. Nat Rev Mol Cell Biol 2003:4:915-925.

39. Baek JH, Birchmeier C, Zenke M, et al. The HGF receptor/Met tyrosine kinase is a key regulator of dendritic cell migration in skin immunity. J Immunol 2012;189:1699-1707.

40. Hazan RB, Phillips GR, Qiao RF, et al. Exogenous expression of $\mathrm{N}$-cadherin in breast cancer cells induces cell migration, invasion, and metastasis. J Cell Biol 2000;148:779-790. 